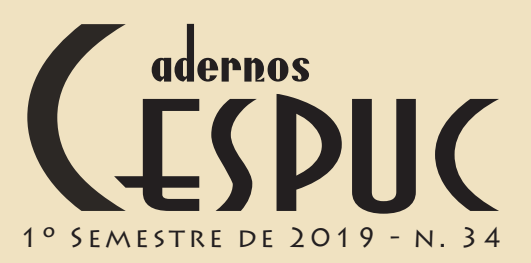

\title{
DRUMMOND: O CIO DA POESIA
}

\section{Audemaro Taranto Goulart*}

Obra, obra, vasta obra. Que fala do homem, da cidade, do povo, da família, dos amigos, do modo de fazer poesia, do simples e do complexo. Obra que faz o leitor rir, que ri do leitor, que faz o leitor chorar porque consegue ser trágica e sublime a um só tempo. Obra que cresceu e ainda cresce porque é contínua na alma das gentes, continua de-cor, no coração das pessoas que não se cansam de lê-la, de declamá-la, de filmá-la. Também se pereniza na lembrança daqueles que não se cansam de falar dela, sofisticadamente, simplesmente, sabiamente.

Obra que começa com o "Poema de sete faces", mas que tem mil faces, anunciadas por um anjo torto que produziu um poeta gauche que prega peças como a da pedra no meio do caminho, como a do cão do "Aliança", como a do imperador Maximiliano, do "Bolero de Ravel". E o anjo torto sai das sombras e, face a face com o leitor, tem a desfaçatez de pregar, ou de propor, uma peça como a do poema "Isso é aquilo". Ante a perplexidade do leitor, o anjo das trevas lhe cicia, irônico: "trouxeste a chave?".

Esse texto, exemplo arquetípico da metapoesia de Drummond, já fez muito leitor, incurioso e lasso, desdenhar a coisa oferta e passar em branco pela magnífica lição de busca da poesia nele estampada. O poema divide-se em duas partes distintas. Na primeira, alinham-se dez estrofes cada uma contendo dez versos. Todos eles apresentam uma estrutura uniforme, marcada sempre pela presença de dois nomes determinados por um artigo definido singular, masculino ou feminino. As exceções ficam por conta do quarto verso da segunda estrofe - "a litotes Aristóteles" - do último verso da nona estrofe - "as endoenças os antibióticos" - e de sete versos da décima estrofe: "o doce de pássaro", "a passa de pêsame”, "a força do destino", "o cudelume ulalume", "o zunzum de Zeus", "o bômbix" e "o ptyx".

A título de ilustração, reproduzo a primeira e a última estrofes.

I

O fácil o fóssil

o míssil o físsil

a arte $\mathrm{o}$ infarte

o ocre o canopo

a urna o farniente

a foice o fascículo

* Professor do Programa de Pós-graduação em Letras da Pontifícia Universidade Católica de Minas Gerais (PUC - Minas). Doutorado em Teoria Literária e Literatura Comparada pela Universidade de São Paulo.

ORCiD: https://orcid.org/0000-0003-4135-4668 


\section{（ESPUC \\ 10 SEMESTRE DE $2019-$ N. 34}

\section{Aludemaro Taranto Goulart}

a lex o judex

o maiô o avô

a ave o mocotó

o só o sambaqui

(ANDRADE, 1988, p. 341)

$\mathrm{X}$

$\mathrm{o}$ árvore a mar

o doce de pássaro

a passa de pêsame

o cio a poesia

a força do destino

a pátria a saciedade

o cudelume Ulalume

o zunzum de Zeus

o bômbix

o ptyx

(ANDRADE, 1988, p. 342)

Após a leitura, curioso, o leitor há de correr ao dicionário, na expectativa de decifrar esse cipoal léxico. (Afinal, a propósito de poemas, o poeta mesmo já dissera: "Ei-los sós e mudos, em estado de dicionário"). Corrida não de todo equivocada, mas quase inútil, como se verá.

A segunda parte tem estrutura inteiramente diversa. Nela os sintagmas são mais explícitos e não teimam tanto naquela redução dramática da primeira parte. Ao encontrá-la, o leitor tem a presunção de ter deparado um remanso, oásis generoso para a sua interpretação. Anima-o a convicção de estar diante da porta através da qual penetrará surdamente no reino das palavras. Que destino o aguarda?

Não querendo passar por vias inesperadas, sigo, ainda que vagaroso e de mãos pensas, pelo pedregoso caminho que leva ao armazém do factível, esse laboratório poético "onde a realidade é maior do que a realidade". Vou de mãos pensas, mas não vazias porque é sempre perigoso estar sozinho diante do esfíngico "decifra-me ou devoro-te" de um poema desafiador. Assim, para que o poema não ria do insóbrio leitor, busco a ajuda de ninguém menos que Freud, na esperança de que a estrada pedregosa que me separa do poema me conduza a uma instância em que reine a possibilidade do encontro de uma luz.

Anima-me, pois, o fato de que, depois que Freud descobriu o inconsciente, muito já se fez no sentido de aprofundar as investigações que querem encontrar as insondáveis razões da criação. Nesse plano, aproveitando as lições freudianas, reponta uma figura importante que é a de um psicólogo alemão, interessado na decifração dos mistérios da criação artística. Estou falando de Anton Ehrenzweig (1977) e do seu "Psicanálise da percepção artística", um livro que trata da teoria da percepção inconsciente. Também não posso esquecer Norman Brown (1974) e seu "Vida contra a morte", onde se pode ver que a linguagem é constituída de amor. É com eles que me sinto em condições de olhar nos olhos da Medusa, no desafiador: "Isso é aquilo". 


\title{
C adernos \\ 1 O SEMESTRE DE $2019-$ N. 34
}

Começo o exercício da leitura: "O fácil o fóssil / o míssil o físsil / a arte / o ocre o canopo / a urna o far-niente / a foice o fascículo / a lex o judex" (ANDRADE, 1988, p. 341). Ó que duro, duro ofício de ler em busca de um sentido, mas, prestando atenção, apurando o ouvido, tudo se dá como se o poema continuasse a ciciar: não busques o sentido, eu já disse alhures que "Não há criação nem morte perante a poesia. / Diante dela, a vida é um sol estático, / não aquece nem ilumina” (ANDRADE, 1988, p. 95).

Continuo lendo o poema e quanto mais nele penetro mais me dou conta da desnecessidade - por impossível mesmo - de buscar um sentido. E vou percebendo que lê-lo é, antes de tudo, fruí-lo. É aí que começo a transitar noutra espécie de terreno. Interessa-me muito mais deixarme envolver por uma melodia em que minha "alma cativa e obcecada / enrola-se infinitamente numa espiral de desejo / e melancolia" (ANDRADE, 1988, p. 64). Assim, sedado, cedo à sensação de ir ao encontro de sua origem, de seu bosque ameno.

Ehrenzweig (1977) já me avisara da humana compulsão ao saber - quer dizer, compulsão à busca do sentido - dizendo que estamos sempre submetidos a um processo imperioso: a formatação que a mente de superfície quer impor a todos os impulsos que brotam do inconsciente. Ah! Impulsos desconhecidos, "a quanto me obrigas", "De dorso curvo e olhar aceso, / troto as avenidas neutras / atrás da sombra que me inculcas" (ANDRADE, 1988, p. 47).

Essa célebre tendência à articulação, conhecida pelo nome de Gestalt, vai promovendo, no nível da mente observadora (de superfície), a descaracterização daquilo que brota da mente profunda. E os detalhes, as sensações dispersas e aparentemente casuais, que certamente conduzem significativos conteúdos inconscientes, vão perdendo-se na escuridão do sentido imposto e, quase sempre, achado.

É por isso que Ehrenzweig diz:

\begin{abstract}
Sob o ponto de vista da Psicologia profunda, as psicologias atuais da arte se preocupam demais com sua ordem superficial e óbvia e com seus recursos estéticos, sendo assim impedidas de apreciar os muitos fenômenos inarticulados da forma que não fazem parte da superestrutura estética da arte (EHRENZWEIG, 1977, 43).
\end{abstract}

Mas nem tudo está perdido. Se Lacan diz que o sentido não existe, mas o sentido insiste, Drummond responde, dizendo que isso é aquilo, e que, na busca dessa "forma", não encontrarte é nenhum desgosto. E para que encontrar um quê, por exemplo, nessa relação? "o dzeta o zeugma / o cemitério a marinha / a flor a canéfora / o pícnico o pícaro / cesto o incesto / o cigarro a formicida / a aorta o Passeio Público / o mingau a migraine / o leste a leitura / a girafa a jitanjáfora" (ANDRADE, 1988, p. 342).

Ora, quando se busca um sentido, muitas vezes encontra-se algo ainda mais surpreendente. É o caso ilustrativo desse "jitanjáfora". O crítico Alfonso Reyes retira a palavra dos versos seguintes, do poeta cubano Mariano Brull: "Filiflama alabe cundre / ala alalúnea alífera / alveola jitanjáfora / liris salumba salífera” (BRULL apud REYES, 1983, p. 85). 


\section{CESPUC \\ 1 O SEMESTRE DE $2019-$ N. 34}

\section{Audemaro Taranto Goulart}

Em seguida, explica que "jitanjáfora" é um "gênero de poema ou fórmula verbal que não se dirige à razão - nem ao sentimento, poderia acrescentar - mas, antes, à sensação e à fantasia". Como se vê, a explicação é, antes, um refugo ao sentido, interessada em liberar o termo de sua camisa-de-força semântica para deixar que, em seu lugar, desbordem as sensações ou, para falar com Ehrenzweig (1977), manifestem-se as forças pulsionais.

Desnecessário é dizer que tais considerações aplicam-se integralmente ao poema de Drummond e para que isso fique claro, tomem-se lá mais esses versos: "o remorso o cós / a noite o bis-coito / o cestércio o consórcio / o ético a ítaca / a preguiça e treliça / o castiço o castigo / o arroz o horror a nespa a véspera / o papa a joaninha / as endoenças os antibióticos" (ANDRADE, 1988, p. 342).

Ora, o que Drummond está fazendo é uma brincadeira. Está ensinando a brincar com palavras, está ensinando a fazer poesia. Diria: antes brincar que lutar com palavras que essa é uma luta mais vã. Drummond brinca, promovendo aproximações fonéticas (como "a preguiça a treliça", "o castiço o castigo"), destacando a semelhança da tonicidade das palavras (como "o ético a ítaca", "o pícnico o pícaro"), invertendo fonemas que criam significantes novos, mas que permanecem evidentes (como "a nespa a vêspera"), alterando determinante e determinado (como "o árvore a mar"). E para que o receptor se satisfaça com um mínimo de descobertas apresenta sugestões bastante salientes (como "a medusa o Pégaso", "o cigarro e formicida"), chegando mesmo a extrair uma palavra de dentro de outra, com o que um sentido parece, enganosamente, luzir. Neste caso está, por exemplo, o último verso do exemplo acima, em que o termo "endoenças" - solenidades religiosas que se celebram na quinta-feira santa - projeta-se o "doenças", que tem tudo a ver com o seu par "antibióticos". Mas o sentido parece esgotar-se nesse artifício lúdico, praticamente não autorizando ao leitor outros voos imaginários em busca de outras relações.

Algo semelhante se poderia dizer da relação que se estabelece no verso "a noite o biscoito", em que a partição da palavra descobre um prefixo que intensifica o significante "coito", projetando uma ironia que é, ao fim, o elemento responsável pela aproximação semântica com o termo "noite". Mas, também aqui, as possibilidades de escandir o sentido estacionam nos arredores das palavras, negando a possibilidade de elucubrações mais agudas. E o que se vê é que o poeta goza, diverte-se com o seu brinquedo, visto que, neste particular, o poema abriga duas coisas muito próximas: "o cio a poesia".

Mas, por que o poeta brinca? Talvez porque brincar com as palavras seja algo que ninguém poderia impedi-lo de fazer, talvez seja o eco das brincadeiras que a infância não conseguiu perenizar, tal como se vê no poema "Brincar na rua", de Boitempo:

Tarde?

O dia dura menos que um dia

O corpo ainda não parou de brincar

e já estão chamando da janela:

É tarde.

Ouço sempre este som: é tarde, tarde. 


\section{CESPUC \\ 1 O SEMESTRE DE $2019-$ N. 34}

\section{Audemaro Taranto Goulart}

A noite chega de manhã?

Só existe a noite e seu sereno?

O mundo não é mais, depois das cinco?

É tarde.

A sombra me proíbe.

Amanhã, mesma coisa.

Sempre tarde antes de ser tarde

(ANDRADE, 1988, p. 499).

Pois é fazendo poesia que Drummond brinca. E agora não tem mais essa de ser tarde. Como disse Freud, a técnica da arte, algo inteiramente diferente da argumentação racional, liga-se ao que ele denomina de processo primário. Nesse sentido, os métodos do inconsciente, radicalmente diversos dos que estruturam o processo consciente, são ilógicos apenas aparentemente. Na verdade, tais métodos oferecem uma viva significação porque estão lidando com uma atividade lúdica que é a linguagem.

Esse aspecto lúdico da linguagem foi enfatizado por Norman Brown (1974, p. 91-92) quando disse: "Não se trata de requinte psicanalítico, mas simples observação da infância, reconhecer que na história de todo ser humano a linguagem origina-se na vida infantil das brincadeiras, do prazer e no amor que a mãe centraliza".

É, pois, com um exercício lúdico que Drummond se compraz na primeira parte do poema, razão por que destaco o verso "o cio da poesia" que aparece na estrofe X como um emblema dessa brincadeira que o poeta faz com as palavras. A poesia, portanto, deixa-se imantar por um apetite, um cio, justamente porque, como diz Norman Brown (1974, p. 92), "se a linguagem tem uma base erótica infantil, deve ser basicamente uma atividade diversória" que busca incessantemente o prazer.

Assim, ao meu ver, "o cio a poesia", esse verso precioso do poema de Drummond, precisa ser destacado porque deveria ecoar, como uma litania, em todo e qualquer poema que se preze. Todo poema que se preze tem de saber dizer seu "isso é aquilo", tem de fazer fulgurar a sua linguagem, como faz Drummond, pelo simples fato de que a linguagem, como se pode observar na psicanálise, é constituída de sexualidade (sublimada). Esse caráter diversório da linguagem mostra que, para a criança, aprender a falar é em si um brinquedo, e essa disposição acompanha o adulto pelo fato mesmo de que está colada na linguagem, razão por que Cassirer insiste em reconhecer nela um aspecto lúdico: "A linguagem é por sua própria natureza e essência, metafórica e toda metáfora é um jogo de palavras".

Esse jogo de palavras é o que se vai descobrindo na leitura do "Isso é aquilo". As palavras vão brotando no poema como se fossem reflexos sem propósito definido, a exemplo das associações livres de ideias. É por isso que elas se apresentam como o resultado de uma varredura no inconsciente, em busca de um prazer que parece provir do encontro de um brinquedo, como se quisesse promover o redescobrimento da infância, visando, sobretudo, ao gozo que a libertação do instinto pode propiciar. E essa manifestação é que se faz, essencialmente, poética, na medida em que projeta o mais-dizer de uma experiência inefável. Tal experiência implica efeitos indizíveis, no contato que se estabelece então com a manifestação da Beleza. O que 


\section{CESPUC \\ 1 O SEMESTRE DE $2019-$ N. 34}

quero dizer é que, nesse ponto, está-se lidando com os efeitos da estética e não é demais também imaginar que isso se dá justamente porque a linguagem seduz sem dizer por que ou seduz porque não tem que dizer nada além de sua mudez. Wittgenstein mesmo não deixou por menos: para ele, uma das linhas de força da filosofia seria exatamente estabelecer uma luta contra o enfeitiçamento da inteligência humana promovido pela linguagem.

Mas a brincadeira do poema faz piruetas. É só observar a sua segunda parte para perceberse uma guinada na sua composição. Agora, tem-se uma forma que se esquiva, mas que, de algum modo, não se enreda na perplexidade da primeira parte. É como se o poeta, rindo (do leitor?), exibisse ali a coisa oferta para que fosse decifrada. Movimenta-se, a expedição dos caçadores do sentido, e com que prazer eles vão em busca dele. Afinal, alguma coisa luz no universo do poema: \\ Forma \\ forma \\ forma}

que se esquiva

por isso mesmo viva

no morto que a procura

a cor não pousa
nem a densidade habita
nessa que antes de ser
já
deixou de ser não será
mas é
forma
festa
fonte
flama
filme
.
e não encontrar-te é nenhum desgosto
pois abarrotas o largo armazém do factível
onde a realidade é maior do que a realidade.
(ANDRADE, 1988, p. 342-3)

Como se pode ver, há, aí, muita sugestão para interpretações. Poderia até mesmo convocar as reflexões de Ehrenzweig (1977), a respeito das formas inarticuladas, para aproximálas do que o poeta coloca. Afinal, as formas inarticuladas, enquanto expressões dos desejos e tendências inconscientes, fluem livremente, independentes da Gestalt e, por isso mesmo, projetam um estado caótico em termos de organização racional.

Poder-se-ia pensar, pois, a primeira parte do poema como exemplo dessa manifestação do 


\section{CESPUC \\ 1 O SEMESTRE DE $2019-$ N. 34}

\section{Audemaro Taranto Goulart}

inconsciente, algo semelhante àquilo que os teóricos do surrealismo chamaram de automatismo psíquico, e a segunda como uma espécie de tentativa de formatar aquelas irrupções da mente profunda. Nesse passo, o analista/intérprete estaria operando uma leitura que procuraria transformar impulsos desinibidos e caóticos numa codificação cujo objetivo seria, sobretudo, apontar o seu rendimento semântico.

Desse modo, não seria difícil trabalhar as analogias que mostram como a forma se esquiva àquele que a procura, pela singular razão de que o sentido é também esquivo e fluido, à maneira daquele "lugar sem ocupante" e daquele "ocupante sem lugar" com que Deleuze (1974, p. 53) se refere ao sentido que transita nas séries do significante e do significado. Quer dizer, é impossível pensar-se no sentido como o habitante de um lugar fixo e pré-determinado. Veja-se que, no poema, essa fluidez está marcada não apenas na enumeração meio caótica, da primeira parte, mas também, na segunda parte, na ideia de que, na forma, "a cor não pousa / nem a densidade habita / nessa que antes de ser / já / deixou de ser não será / mas é" (ANDRADE, 1988, 342).

Ante essa busca irremediável do sentido - esse fantasma que faz a linguagem, que move a vida e promove o neurótico mal-estar do mundo da cultura - o poeta, ironicamente, reconhece: "e não encontrar-te é nenhum desgosto / pois abarrotas o largo armazém do factível / onde a realidade é maior do que a realidade” (ANDRADE, 1988, p. 343).

Aí está um escasso rendimento da caça ao sentido. Mas prefiro deixar a expedição e voltar a transitar no mundo das sensações que o texto de Drummond desperta. É desse modo que me sinto mais confortável para buscar uma articulação entre a primeira e a segunda partes do poema.

E como fazê-lo? Mais uma vez, Freud explica.

O caráter lúdico da primeira parte de "Isso é aquilo" lembrou-me Freud e suas formulações sobre o chiste. Sabe-se que, no chiste, há um desvio do curso da linguagem ou do pensamento racional, ocorrendo, então, um contraste de representações, o que fica muito claro quando se percebe que, de fato, no chiste apresenta-se um sentido no "sem sentido", no nonsense, ou seja, no disparate. Na verdade, essa aparente impropriedade se deve ao fato de haver uma conexão ou enlace arbitrário de duas representações, através de uma associação linguística. E isso se deve ao fato de que, escapando ao controle racional da mente de superfície, o dito chistoso consegue liberar o gozo das pulsões primordiais. É por isso que, no chiste, faz-se presente um significado que só cabe ali, naquele momento, sendo impossível que ele possa ser reaproveitado em outro contexto ou que continue existindo depois de ter sido dito.

Quando abordou a questão do mecanismo do prazer e a psicogênese do chiste, Freud impôs-se verificar de que modo a técnica e as tendências desse mecanismo funcionam como fontes produtoras do prazer. Enuncia, então, a modalidade de ação do chamado chiste tendencioso, princípio que opera no sentido de fazer com que, de um prazer prévio, decorra um novo prazer, motivado este pela eliminação de repressões. Freud mostra que o chiste faz um percurso, mantendo uma essência coerente do princípio até o seu final. Inicialmente, ele busca o prazer pelo livre emprego de palavras e pensamentos sem sentido. Intervém, neste instante, 


\section{CESPUC}

\section{Audemaro Taranto Goulart}

uma censura que se faz a esse jogo de palavras, o que provoca um retorno à pilhéria, com o objetivo de manter aquelas fontes do prazer primitivo, do que resulta um prazer derivado do disparate que tivera lugar.

Desse modo, é preciso dizer que a graça ou o divertimento presentes no chiste servem como uma espécie de anúncio de um prazer maior que será, justamente, o que vem depois: a liberação de desejos reprimidos.

Nesse aspecto, Norman Brown (1974) lembra a analogia instigante que Freud estabeleceu entre o elemento lúdico e o elemento de libertação do instinto, no chiste, e a questão do prazer prévio e prazer final, nas relações sexuais, uma vez que nestas o prazer prévio é uma espécie de evocação daquele prazer que a criança deriva quando passa pelas fases que compõem o seu desenvolvimento psicossexual. É algo, pois, da sexualidade infantil, diferente do prazer do orgasmo que, no adulto, tem uma configuração eminentemente genital.

As colocações de Freud sobre o chiste parecem projetar uma teoria psicanalítica da arte. Nesse sentido, há que pensar a arte como prazer, como brinquedo, diria mesmo, arte como liberadora do instinto, como redescobrimento da infância.

E é também aí que fico pensando no poema de Drummond e nas suas duas partes. Nele, tudo parece ligar-se a esses conceitos explicitados. $\mathrm{O}$ brinquedo com a linguagem, tal como se mostrou na primeira parte do poema, e o prazer que alcança o leitor, a partir dos efeitos obtidos, funcionam como aquela espécie de prazer prévio que anuncia um prazer derivado. E isso pode ser vislumbrado na medida em que se percebe que a forma caótica da primeira parte funciona como um componente que atinge um elevado grau de excitação justamente porque propõe um enigma que é, sobretudo, um refugo ao sentido. Tal tensão se aplaca no instante em que o leitor alcança a segunda parte do poema. Na verdade, o que ele parece alcançar é uma placidez orgástica ao perceber que ali há uma possibilidade de um saber que lhe escapava.

É pertinente pensar, pois, a primeira parte do poema como exemplo da manifestação do inconsciente, algo semelhante àquilo que os teóricos do surrealismo chamaram de automatismo psíquico, e a segunda como uma espécie de tentativa de formatar aquelas irrupções da mente profunda. Nesse passo, o analista/intérprete estaria operando uma leitura que procuraria transformar impulsos desinibidos e caóticos numa codificação cujo objetivo seria, sobretudo, apontar o seu rendimento semântico.

Desse modo, não seria difícil trabalhar as analogias que mostram como a forma se esquiva àquele que a procura, pela singular razão de que o sentido é também esquivo e fluido, à maneira daquele "lugar sem ocupante" e daquele "ocupante sem lugar" com que Deleuze se refere ao sentido que transita entre o significante e o significado. Quer dizer, é impossível pensar-se no sentido como o habitante de um lugar fixo e pré-determinado. Veja-se que, no poema, essa fluidez está bem marcada na enumeração meio caótica, da primeira parte, o que leva o leitor a uma busca exasperada do sentido e que acaba tendo um escasso rendimento.

Mas prefiro voltar ao mundo das sensações que o texto de Drummond desperta. É desse modo que me sinto mais confortável para buscar uma articulação entre a primeira e a 


\section{CESPUC \\ 10 SEMESTRE DE $2019-$ N. 34}

\section{Audemaro Taranto Goulart}

segunda partes do poema.

Veja-se que, na segunda parte, em que há uma inegável concatenação de palavras que mostram uma organicidade do discurso poético, o leitor pode se dar ao prazer de encontrar significações muito mais compreensíveis. Transcrevo, então, os versos iniciais da segunda parte, para destacar aspectos que me parecem relevantes:

F
Forma
forma
forma

que se esquiva

por isso mesmo viva

no morto que a procura

Como se vê, o texto se inicia com uma articulação do significante " $F$ " que vai se desdobrar no corresponde "Forma" (com "F" maiúsculo), seguido de dois outros significantes "forma" com "f" minúsculo. Quer dizer, a "forma" começa a se caracterizar. Fazendo um jogo de palavras, diria que "a Forma começa a ganhar forma". Note-se, entretanto, pelo que vem nos versos seguintes, que o sentido "se esquiva", e justamente esse dinamismo é revelador da condição viva que imanta a forma que parece fugir daquele ser inerte/ morto (o leitor) que a procura. Essa oposição "viva" (da forma) versus "morto" (do leitor) é bastante pertinente para mostrar o enorme trabalho da busca do sentido. Essa busca é condição essencial para operar aquela espécie de prazer preliminar que vai resultar no gozo orgástico final quando do encontro do sentido.

Os versos que vêm a seguir são elucidativos para que se tome a forma como as "formas inarticuladas" de que fala Ehrenzweig (1977, p. 42): "Nós veremos que tais experiências, de formas inarticuladas, ora aparecem como um todo vazio, como "intervalos" ou interrupções no fluxo da consciência, ora adquirem, ao contrário, uma estrutura excessivamente articulada e definida". É preciso, pois, estar atento para o fato de que as formas inarticuladas, pelo fato mesmo de se situarem no nível do inconsciente, exigem uma atenção especial do leitor para que possam ser bem compreendidas e bem interpretadas ou traduzidas no nível articulado da consciência.

Veja-se que os versos são expressivos para mostrar como se processam as formas inarticuladas:

\footnotetext{
a cor não pousa

nem a densidade habita

nessa que antes de ser

já

deixou de ser não será

mas é
} 
Pelo que está nesta parte do texto, vê-se que a forma não tem "cor" nem "densidade", o que sugere com muita propriedade que as formas inarticuladas têm um caráter indefinido, não específico, não formatado. Mas é importante chamar a atenção para o fato de que, mesmo não tendo um desenho definido, palpável, a forma inarticulada parece não existir (nem antes - "antes de ser" -, nem agora - "já deixou de ser" - nem no futuro - "não será"), mas o fato é que "ela é", ou seja, ela existe e muito, só que essa forma, melhor dizendo, essas formas inarticuladas habitam o inconsciente, esse locus que, para o sujeito, é desconhecido, intangível, inacessível, só podendo ser reconhecido através de determinadas manifestações de uma força agente que o encobre, mas que atua incessantemente no seu interior.

Chega-se, assim, ao final do poema. Ali estão sugestões bastante pertinentes para mostrar a força e o movimento das formas inarticuladas. Elas são "forma, festa, fonte, flama, filme". Elas são o júbilo de uma força que se projeta na direção do prazer, são a origem e causa de todo procedimento humano, são "o fogo que arde sem se ver", como disse Camões, são a própria história que se conta do sujeito e que pode ser resgatada numa narrativa como no sonho e em outras instâncias tal como coloca Jacques Lacan, ao mostrar as possibilidades de se ler a presença do inconsciente. Tais leituras podem ser feitas:

a) no corpo, onde o sintoma manifesta a estrutura de uma linguagem;

b) nos documentos de arquivo, que são as lembranças que revelam uma evocação da trajetória do sujeito;

c) na manifestação semântica, caracterizada através do vocabulário que é próprio do indivíduo;

d) nas tradições, ou seja, nas lendas que veiculam a história do ser;

e) nos vestígios que mostram os capítulos falsificados do percurso que o sujeito realiza e os capítulos que contêm essas falsificações (LACAN,1998, p. 260).

Chame-se a atenção para o ponto que se encontra antes dos três últimos versos. Ele como que encerra o movimento que agencia as significações que podem ter as formas inarticuladas. Note-se ainda que não encontrar tais formas não representa nenhum desgosto, pois, como se viu, seu caráter fugidio, impalpável e não figurado é algo que repele um encontro transparente e lúcido. Mas o certo é que elas abarrotam o largo armazém do factível Esse armazém é o próprio inconsciente, com sua força e impulsos incontroláveis, com sua poderosa onipresença que dirige o ser e o conduz como bem quiser. Nesse locus, a realidade é maior do que a realidade, visto que a usina que é o inconsciente é muitas vezes superior à minúscula realidade onde o sujeito vive e transita. Não é por outra razão que Freud afirmou que o inconsciente tirou o homem do confortável lugar em que ele vivia a ilusão de ser o centro de si mesmo.

Drummond foi um poeta que trabalhou muito a chamada dimensão metaliterária dos seus textos. São inúmeros os exemplos, mas suponho que em nenhum deles se projeta o perfil da criação poética de modo tão nítido quanto neste "Isso é aquilo". 


\section{REFERÊNCIAS}

BROWN, Norman O. Vida contra morte - O sentido psicanalítico da História. 2 ${ }^{a}$. ed. Tradução de Nathanael C. Caixeiro, Petrópolis: Vozes, 1974.

ANDRADE, Carlos Drummond de. Poesia e prosa. Rio de Janeiro: Editora Nova Aguilar, 1988.

DELEUZE, Gilles. Lógica do sentido. Tradução de Luiz Roberto S. Fortes. São Paulo: Perspectiva/Edusp, 1974.

EHRENZWEIG, Anton. Psicanálise da percepção artística - Uma introdução à Teoria da Percepção Inconsciente. Tradução de Irley Franco. Rio de Janeiro: Zahar Editores, 1977.

REYES, Alfonso. La experiência literária. México: FCE, 1983.

FREUD, S. El chiste y su relación con lo inconciente. In: Sigmund Freud - Obras completas, v. 8, Buenos Aires: Amorrortu editores, 1993.

LACAN, Jacques. Escritos. Tradução de Vera Ribeiro. Rio de Janeiro: Jorge Zahr Editor, 1998. 